\title{
Definição das Unidades de Relevo na Bacia Hidrográfica do Rio Jaguari - Deste do RS
}

\section{Definition of Relief Units in the Basin Jaguari River - RS West}

Vinicius Silveira dos Santos *

Luís Eduardo de Souza Robaina **

Romario Trentin **

\begin{abstract}
Resumo:
Analisar as características físicas do relevo, superfície onde ocorre a interação homem e natureza, e entende-las, contribui na abordagem dos estudos ambientais voltados para o planejamento e manejo adequado do espaço geográfico. O presente trabalho, como objetivo de contribuir nos estudos ambientais, propõe a definição das Unidades de Relevo da Bacia Hidrográfica do Rio Jaguari, na região Oeste do Estado do Rio Grande do Sul, a partir de um banco de dados cartográfico georreferenciado. Nessa perspectiva, entender como o relevo se distribui, é imprescindível para as questões voltadas para uma gestão ambiental adequada.
\end{abstract}

* Mestrando em Geografia pela UFSM

** Prof. Dr. do Departamento de Geociências da UFSM. Pesquisador do Laboratório de Geologia Ambiental (LAGEOLAM

Abstract:

Palavras-chave:

Analyze the physical characteristics of relief, surface where the interaction between man and nature is, and understand them, contributes in addressing the environmental studies focused on planning and proper management of the geographical space. This work aimed to contribute in environmental studies, proposes the definition of Basin Relief Units Jaguari River in the State of Rio Grande Western region South, from a database of georeferenced cartographic data. In this perspective, understand how the relief is distributed, it is essential to the questions related to proper environmental management.

Relevo,

Rio Jaguari, SIG.

Key-Words:

Relief, Jaguari river, GIS. 


\section{INTRODUÇÃO}

A apropriação dos recursos naturais pelo hoImem, vem crescendo consideravelmente, atendendo a uma grande demanda econômica e social, sem se ter a preocupação pela preservação e manutenção das formas naturais do espaço geográfico.

Dessa forma, o espaço geográfico apresenta-se em constante transformação, sendo esses processos modeladores oriundos de ações naturais (fatores endógenos e exógenos) ou oriundos de ações antrópica, tendo o homem o papel de principal acelerador dos processos alteradores da paisagem.

O relevo, superfície em que ocorre a interação entre o homem e a natureza, apresenta-se como temática fundamental para estudos ambientais, sendo o elemento caracterizador da paisagem.

Alguns dos primeiros estudos que analisaram e classificaram o relevo a partir de parâmetros morfométricos (baseando-se no comportamento de fluxos superficiais em vertentes) foram desenvolvidos por Troeh (1965) e Huggett (1975). No Brasil destacam-se os trabalhos desenvolvidos pelo projeto RADAMBRASIL (1986).

Na região Oeste do Rio Grande do Sul, destacam-se trabalhos desenvolvidos por De Nardin et al (2005), Trentin et al (2012) e Sccoti et al (2013) utilizando a proposta de definição de unidades de relevo, a partir de parâmetros altimétricos, correlacionando com parâmetros de declividade e as formas das encostas.

Os métodos de classificação atuais possibilitam a subdivisão das formas em elementos do relevo, que são um conjunto de parcelas de um tipo de relevo relativamente homogênea em relação a curvaturas de perfil e de plano, inclinação, orientação e posicionamento na paisagem (MACMILLAN E SHARY, 2009).

As bacias hidrográficas apresentam-se como a materialização de diferentes elementos integradores do meio físico, resultado dos processos modeladores atuantes no relevo, caracterizando um sistema exposto a intervenções. Dessa forma, representam unidades fundamentais para os estudos ambientais.

Nas análises ambientais a utilização de um banco de dados cartográfico manipulados em SIG (Sistemas de Informação Geográficas) permite a obtenção das características do relevo e o processamento de modo rápido e eficiente. A parametrização da morfologia do relevo por meio de SIG é o processo de extração de atributos quanti- tativos da topografia.

Diante disso, Muñoz (2009), descreve de forma quantitativa as formas da superfície da Terra por meio de equações aplicadas a modelos numéricos de representação altimétrica.

Frente a isso, o presente trabalho traz como proposta a definição das Unidades de Relevo da Bacia Hidrográfica do Rio Jaguari (BHRJ), situada na região oeste do Estado do Rio Grande do Sul (Figura 01), a partir do cruzamento em ambiente de SIG, de um banco de dados georreferenciado, de modo que o software, possa contribuir na caracterização das Unidades de Relevo de modo automático.

\section{MATERIAL E MÉTODOS}

Para o desenvolvimento do trabalho, foram utilizadas bases cartográficas em formato Vetorial e formato Raster, sendo que o banco de dados no formato vetorial está em escala 1: 50.000, disponível pelo trabalho de Hasenack e Weber (2010). As informações extraídas da base cartográfica vetorial do Estado do Rio Grande do Sul foram: hidrografia, limites municipais e o sistema viário.

A base cartográfica no formato Raster, possibilitou a análise dos elementos fisiográficos do relevo (hipsometria, declividade) a partir das informações altimétricas obtidas na imagem SRTM (Shuttle Radar Topography Misson) com resolução de 30 metros, sendo estes dados processados na interface do software ArcGis versão 10.1. Para a definição das formas de vertentes, utilizou-se a imagem SRTM - resolução de 90 metros, devido a melhor representação altimétrica para a definição das formas de encostas, ou seja, um maior número de pixels homogêneos.

A utilização dessas informações para a análise quantitativa do relevo, oferecem subsídios para a análise espacial, através de ferramentas oferecidas pelo SIG, facilitando a tarefa de integração das informações topográficas.

O mapa hipsométrico e o mapa de declividade, são produtos gerados a partir de Modelos Numéricos do Terreno (MNT), que representam uma grandeza que varia continuadamente no espaço. Na manipulação do MNT, utilizou-se a ferramenta "Fill", que tem a finalidade de corrigir os pixels nulos, adquirindo a média altimétrica dos pixels vizinhos.

Os dados referentes à hipsometria, foram gerados pela ferramenta Arc'Toolbox "Topo to Raster", resultado das interpolações referentes aos parâmetros altimétricos. As classes hipsométricas foram definidas através de quebras no relevo e arredondamentos matemáticos: São elas: $<100 \mathrm{~m}$; 100-200m; 200-300m; 400-500m; >500m. 


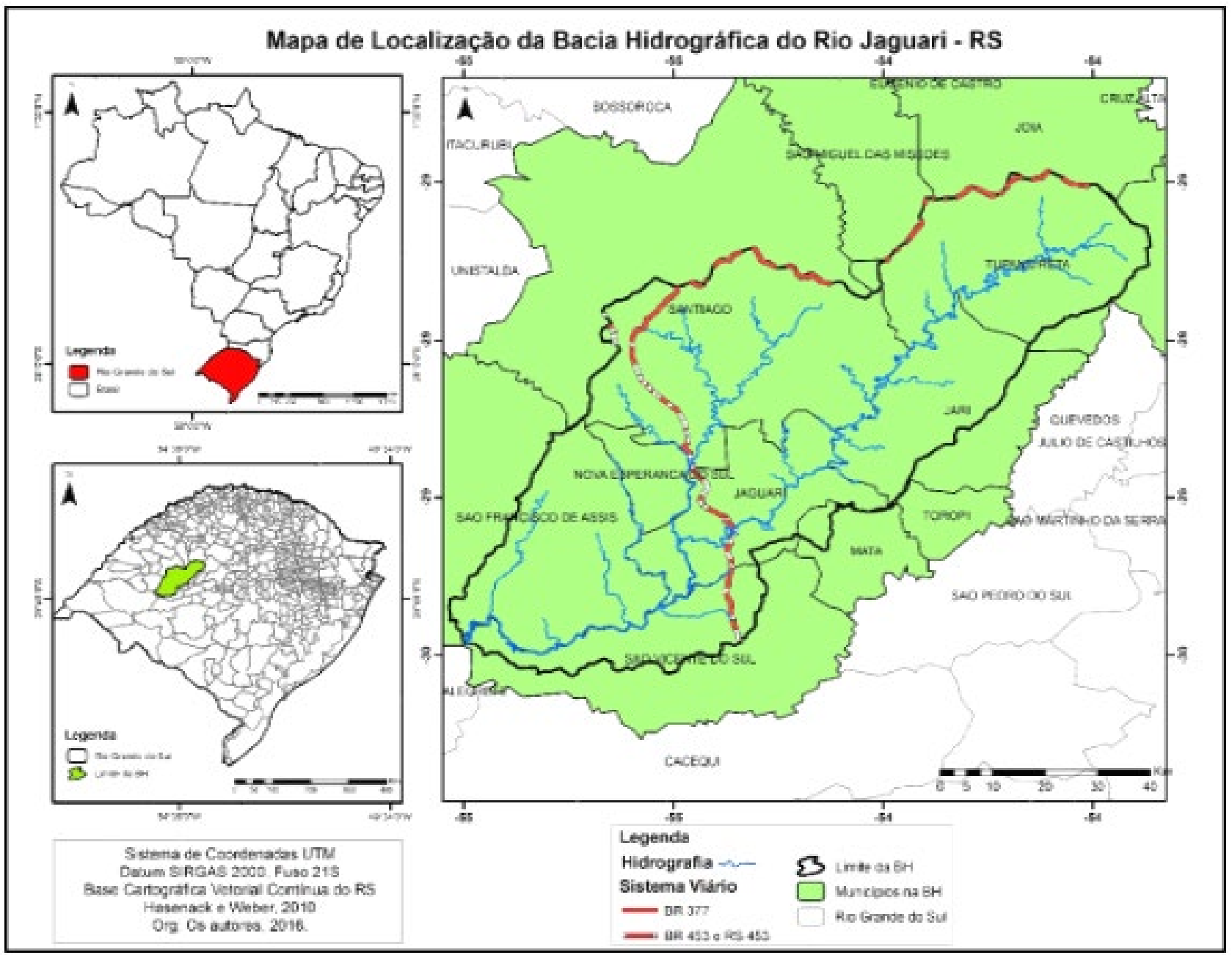

Figura 01 - Mapa de Localização da BHRJ.

Org: Os autores, 2016.

Os parâmetros de declividade, foram gerados pela ferramenta ArcToolbox "Slope", a partir das informações do MNT, utilizando como parâmetros para a definição das classes de declividade, a classificação proposta pelo Instituto de Pesquisas Tecnológicas (IPT), sendo elas: < 2\%; 2-5\%; $5-15 \%$; e $>15 \%$. Com esta classificação, consegue-se visualizar no mapa temático, as classes bem distribuídas sobre o terreno.

Os dados relacionados à curvatura das vertentes, deu-se através da ferramenta ArcToolbox "Curvature", onde é gerado as feições referentes ao Plano de Curvatura (vertentes Convergente e vertentes Divergentes) e Perfil de Curvatura (vertentes Côncava e vertente Convexa).

A feição curvatura Divergente - Convergente refere-se à curvatura no Plano, enquanto que a curvatura Convexa - Côncava refere-se ao Perfil. A curvatura Divergente - Convergente está relacionada à direção ortogonal da vertente influencia na difusão e na concentração de fluxo, enquanto que a curvatura Convexa - Côncava refere-se à direção de orientação, influenciando na velocidade de escoamento da água.
Tabela 01- Caracterização dos processos erosivos em relação à declividade

\begin{tabular}{|c|c|}
\hline Declividade & Influência nos processos erosivos \\
\hline$<2 \%$ & $\begin{array}{l}\text { Áreas planas em geral associadas às drenagens e sujeitas a ocorrência de } \\
\text { inundaçōes e os principais processos estão ligados a deposição de } \\
\text { sedimentos. }\end{array}$ \\
\hline $2-5 \%$ & $\begin{array}{l}\text { Áreas com baixa declividade, porém alguns processos erosivos se tornam } \\
\text { significativos. }\end{array}$ \\
\hline $5-15 \%$ & Áreas com declividades consideráveis, com a atuação de processos erosivos. \\
\hline$>15 \%$ & $\begin{array}{l}\text { Areas com o limite máximo para o emprego da mecanização da agricultura, e } \\
\text { também delimita áreas propicias a ocorrência de processos de movimento de } \\
\text { massa e escorregamentos. }\end{array}$ \\
\hline
\end{tabular}

Org: Os autores, 2016.

Utilizou-se para a definição das formas de vertentes, a partir de combinações das formas, a ferramenta "Combine”. Após o processamento dos dados, as combinações analisadas foram classificadas em: Côncavo - Convergente, Convexo - Convergente, Côncavo - Divergente e Convexo - Convergente.

O histograma de frequência (Figura 02) obtido atra- 
vés do software ArcGis 10.1, define as cotas altimétricas máximas de (Maximum) e cotas mínimas (Minimum) e a média (Mean) das altimetrias distribuídas por esta classe, que permite entender quantitativamente as amplitudes de cada Unidade de Relevo.

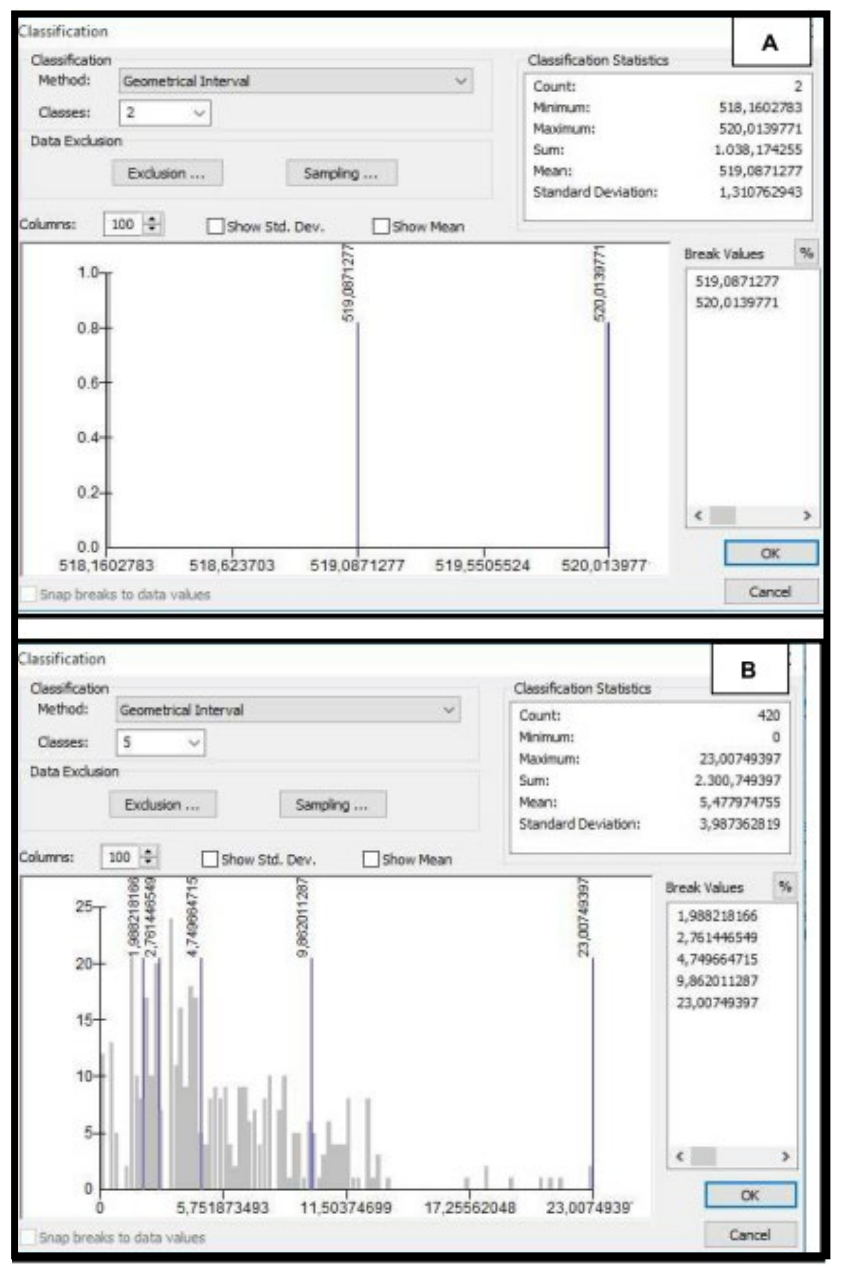

Figura 02: A) Classificação estatística dos dados hipsométricos. B) Classificação estatística dos dados de declividade.

Org: Os autores.

As formas do relevo são indicadas pela quantificação da amplitude e da declividade das encostas, baseando-se no método de classificação adotado por De Nardin (2005), em sua pesquisa. $\mathrm{O}$ método pode ser representado pela Tabela 02 .

Sendo assim, realizou-se a vetorização das Unidades de Relevo, sendo possível posteriormente a correlação das informações visuais (mapa temático) com os dados quantitativos disponíveis pelo histograma de frequência, e caracterizar as Unidades de Relevo na BHRJ. Para uma melhor caraterização das Unidades de Relevo, gerou-se 4 (quatro) perfis topográficos, exceto na Unidade Áreas Planas, devido à baixa representação que esta unidade apresenta.
Tabela 02 - Classificação dos tipos de relevo

\begin{tabular}{rccc}
\hline $\begin{array}{c}\text { AMPLITUDE } \\
\text { ALTIMÉTRICA }\end{array}$ & DECLIVIDADE & Altitude & $\begin{array}{c}\text { UNIDADE DE } \\
\text { RELEVO }\end{array}$ \\
\hline & $<2 \%$ & 90 & $\begin{array}{c}\text { Areas Planas } \\
\text { Colinas Suavemente } \\
\text { Onduladas }\end{array}$ \\
\cline { 2 - 4 }$<100$ metros & $2-5 \%$ & $100 \mathrm{~m}$ & $\begin{array}{c}\text { Colinas } \\
\text { Colinas de Altitude }\end{array}$ \\
\cline { 2 - 4 } & $5-15 \%$ & $300 \mathrm{~m}$ & Morrotes Isolados \\
\cline { 2 - 4 } & $>15 \%$ & $160 \mathrm{~m}$ & Morros \\
\hline$>100$ metros & $>15 \%$ & $120 \mathrm{~m}$ & \\
\hline
\end{tabular}

Fonte: De Nardin, 2005.

\section{RESULTADOS E DISCUSSÃO}

A BHRJ apresenta uma área de $5.149,73 \mathrm{~km}^{2}$, sendo que o canal principal apresenta hierarquia máxima de $6^{\mathrm{a}}$ ordem. O Rio Jaguari é um dos principais afluentes do Rio Ibicuí, sendo este um dos principais tributários à margem esquerda do Rio Uruguai.

A análise da hipsometria apresenta as diferentes altitudes distribuídas na área de estudo, comparadas ao nível do mar.

A bacia hidrográfica caracteriza-se com uma amplitude altimétrica de 468 metros, sendo a menor cota de 76 metros, localizada próxima à foz do rio, e a maior cota é de 544 metros, localizada ao norte da bacia hidrográfica.

Predominam altitudes que variam de 300 à 400m (Figura 03), ocupando 40,64\% da área total da bacia hidrográfica, conforme a Tabela 02 , caracterizando a região geomorfológica do Planalto.

As altitudes entre 100 à 200m, ocupando 19,81\% da área total, apresentam baixas altitudes, caracterizando o relevo em porções planas, que definirá a forma de escoamento no canal principal.

Altitudes entre 200 à 300m, ocupando 16,15\% da área total, caracterizam claramente a região de Rebordo do Planalto, com declives acentuados, que acabam influenciando nas formas das vertentes.

Altitudes entre 400 à 500m, ocupam 14,47\% da área total, distribuem-se à nordeste e oeste da bacia hidrográfica, estando o canal principal situado em altitudes de $433 \mathrm{~m}$ e com declividades de 5,05\%.

Altitudes superiores à $500 \mathrm{~m}$, ocupam uma menor área na bacia hidrográfica $(0,57 \%)$, caracterizando o Planalto Meridional à nordeste da BHRJ.

A declividade das encostas, influencia diversos fatores que contribuem nos processos alteradores nas formas das vertentes, como os movimentos de massa, e processos erosivos, além de interferirem nos processos de uso e ocupação dos solos (Tabela 04).

Os declives entre 5 - 15\% predominam-se na bacia 
hidrográfica, com uma área de 2.535,92 km². Essas declividades são visualizadas no alto curso da bacia (Figura 04), caracterizando o relevo em Colinas Fortemente Onduladas ou de Altitudes no Planalto Meridional.

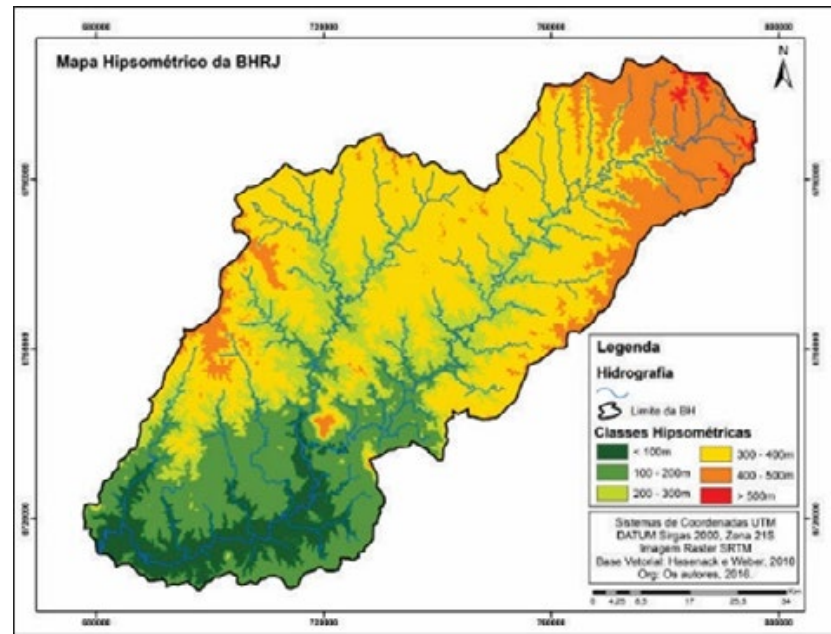

Figura 03 - Mapa hipsométrico da BHRJ.

Org: Os autores.

Tabela 03: Resultados referentes à área e porcentagem de cada classe hipsométrica

\begin{tabular}{c|c|c}
\hline Classes & Área $\left(\mathbf{k m}^{2}\right)$ & Porcentagem (\%) \\
\hline$<100 \mathrm{~m}$ & 430,98 & 8,36 \\
\hline $100-200 \mathrm{~m}$ & 1020,43 & 19,81 \\
\hline $200-300 \mathrm{~m}$ & 832,18 & 16,15 \\
\hline $300-400 \mathrm{~m}$ & 2093,27 & 40,64 \\
\hline $400-500 \mathrm{~m}$ & 745,30 & 14,47 \\
\hline$>500 \mathrm{~m}$ & 27,57 & 0,57 \\
\hline Total & $5.149,73$ & 100 \\
\hline
\end{tabular}

Org: Os autores.

Em sequência, os declives entre 2 - 5\% (1.222,82 $\mathrm{km}^{2}$ ) caracterizam o relevo em Colinas Suaves associadas a áreas do baixo curso do rio principal, na Depressão Periférica.

As declividades menores que $2 \%\left(709,67 \mathrm{~km}^{2}\right)$, caracterizam o relevo em Áreas Planas, localizados junto a foz do canal principal. Nesses declives, a deposição de sedimentos transportados pelos canais é considerável, surgindo bancos de areia. Além disso, nessa região é propicia a cultura de plantações de arroz.

E por fim, os declives maiores que 15\% (681,32 $\mathrm{km}^{2}$ ), caracterizam o relevo em Associações de Morros e Morrotes. Esses declives representam o Rebordo do Planalto, região de transição entre o Planalto Meridional e a Depressão Periférica. Além disso, há presença de Morrotes Isolados em regiões planas, representado por esta classe de declividade.

As encostas são descritas como um elemento da superfície terrestre inclinado em relação a horizontal, que apresenta um gradiente e uma orientação no espaço.

As encostas, Côncava - Divergente apresentam- se com a maior área $1.837,50 \mathrm{~km}^{2}$, representando $35,68 \%$ da área total (Tabela 05), sendo que em subsequência, aparecem com maiores áreas de abrangência, as formas Convexa - Divergente, Convexa - Convergente e Côncava - Divergente, com áreas respectivamente, 1.689,91 km² (32,81\%), 826,10 $\mathrm{km}^{2}(16,04 \%)$ e $796,22(15,47 \%)$, conforme se visualiza na figura 5 .

Tabela 04- Resultados referentes à área e porcentagem das classes de declividade

\begin{tabular}{c|c|c}
\hline Classes & Área $\left(\mathbf{k m}^{2}\right)$ & Porcentagem $(\%)$ \\
\hline$<2 \%$ & 709,67 & 13,78 \\
\hline $2-5 \%$ & $1.222,82$ & 23,75 \\
\hline $5-15 \%$ & $2.535,92$ & 49,24 \\
\hline$>15 \%$ & 681,32 & 13,23 \\
\hline Total & $\mathbf{5 . 1 4 9 , 7 3}$ & 100 \\
\hline
\end{tabular}

Org: Os autores.

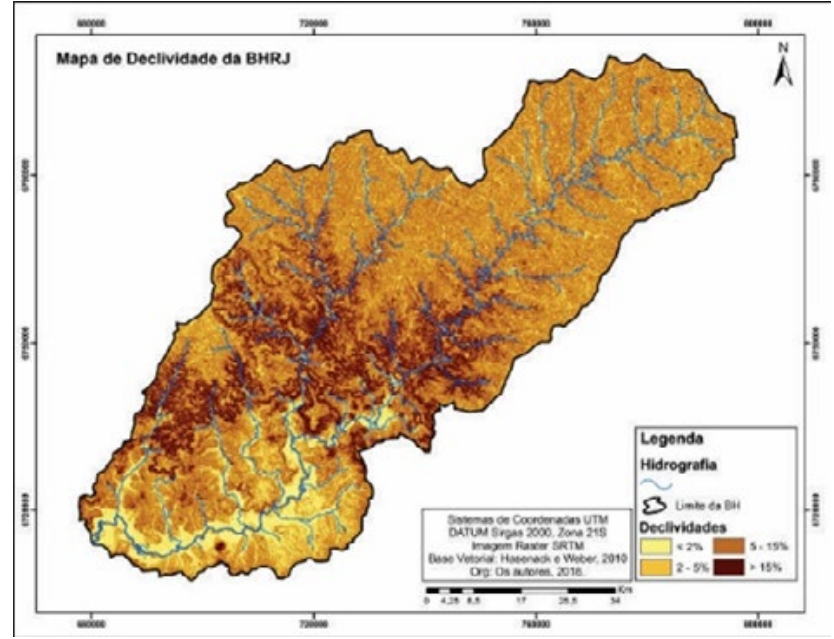

Figura 04- Mapa de Declividade da BHRJ Org: Os autores.

Tabela 05- Tabela da distribuição das formas de vertentes sobre área total da BHRJ

\begin{tabular}{c|c|c}
\hline Classes & Área $\left(\mathbf{k m}^{2}\right)$ & Porcentagem (\%) \\
\hline Côncava - Divergente & $1.837,50$ & 35,68 \\
\hline Convexa - Divergente & $1.689,91$ & 32,81 \\
\hline Convexa - Convergente & 826,10 & 16,04 \\
\hline Côncava - Divergente & 796,22 & 15,47 \\
\hline Total & $\mathbf{5 . 1 4 9 , 7 3}$ & 100 \\
\hline
\end{tabular}

Org: Os autores.

Sob a análise do histograma, referentes aos dados altimétricos da bacia hidrográfica, permite- se averiguar e correlacionar os mapas temáticos (visual) com os valores obtidos de descrição das características físicas do relevo, podendo assim, caracterizar-se as Unidades de Relevo (Tabela 06).

\subsection{Unidades de Relevo}

$\mathrm{Na}$ interpolação dos dados altimétricos, para a definição das Unidades de Relevo, consegue-se visualizar a distribuição das mesmas (Figura 06), dentro da área de estudo. 


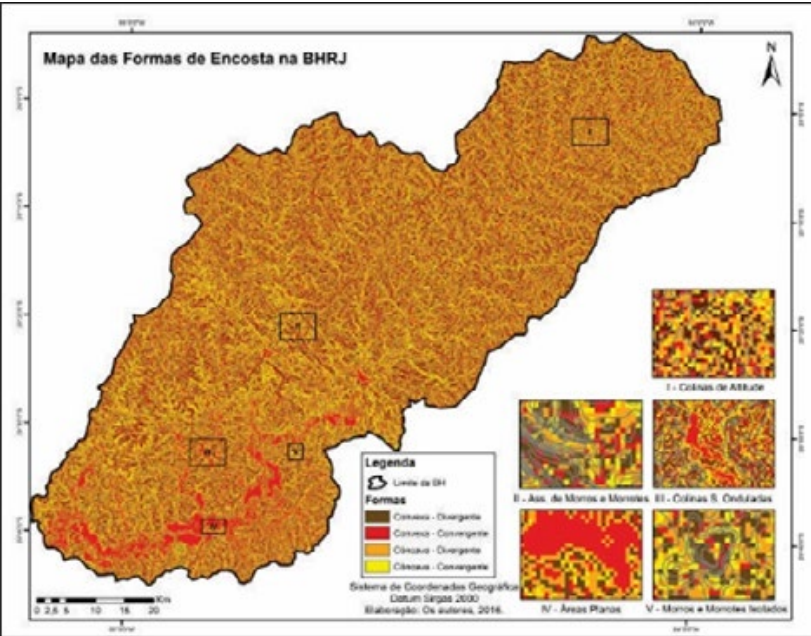

Figura 05- Mapa das Formas de Encostas na BHRJ. Org: Os autores.

Tabela 06 - Amplitudes por Unidades de Relevo

\begin{tabular}{c|c|c}
\hline Amplitude Altimétrica & Declividade & Unidades de Relevo \\
\hline $40 \mathrm{~m}$ & $5-15 \%$ & Colinas de Altitude \\
\hline $260 \mathrm{~m}$ & $>15 \%$ & Associação de Morros e Morrotes \\
\hline $50 \mathrm{~m}$ & $2-5 \%$ & Colinas Suavemente Onduladas \\
\hline $120 \mathrm{~m}$ & $>15 \%$ & Morros e Morrotes Isolados \\
\hline $10 \mathrm{~m}$ & $<2 \%$ & Areas Planas \\
\hline Org: Os autores & &
\end{tabular}

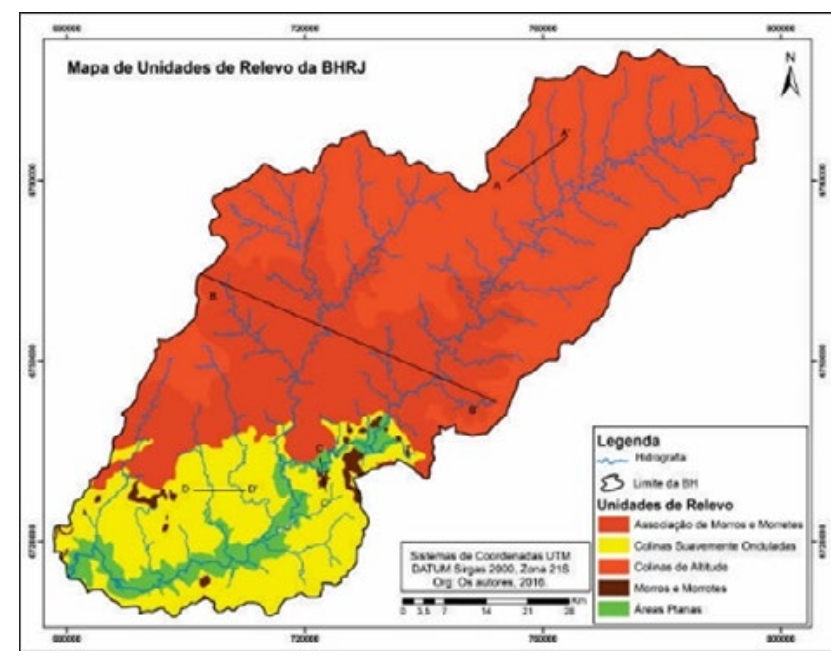

Figura 06- Mapa de Unidades de Relevo da BHRJ. Org: Os autores, 2016.

As Unidades de Relevo serão analisadas, em ordem decrescente, em relação área (Tabela 07) na BHRJ:

Tabela 07- Tabela da distribuição das Unidades de Relevo sobre área total da BHRJ.

\begin{tabular}{c|c|c}
\hline Unidades de Relevo & Área $\left(\mathbf{k m}^{2}\right)$ & Porcentagem (\%) \\
\hline Colinas de Altitude & $2.424,17$ & 47,07 \\
\hline Associação de Morros e Morrotes & $1.482,63$ & 28,79 \\
\hline Colinas Suavemente Onduladas & 944,44 & 18,33 \\
\hline Áreas Planas & 253,69 & 4,92 \\
\hline Morros e Morrotes Isolados & 44,77 & 0,89 \\
\hline Total & $\mathbf{5 . 1 4 9 , 7 3}$ & $\mathbf{1 0 0}$ \\
\hline
\end{tabular}

Org: Os autores, 2016.

\subsubsection{Unidade Colinas de Altitude}

A unidade Colinas de Altitudes apresenta área de $2.424,17 \mathrm{~km}^{2}$, representando $47,07 \%$ da área total. Esta unidade localiza-se com maior abrangência ao norte da bacia, além de estender-se na porção oeste e leste da área de estudo. A unidade apresenta amplitude altimétrica média de $40 \mathrm{~m}$, sendo considerado Colinas de Altitude, com altimetria superior a 300m, e amplitude inferior à 100m, e declividades variando entre $5-15 \%$.

Estes declives são visualizados no alto curso da bacia, condicionando a atividades agrícolas, por exemplo, muito intensa nas regiões do Planalto Meridional. As formas de vertentes Côncava - Divergente distribuem -se pela unidade, caracterizando no fluxo d' água acumulado, sendo influenciado pela forma da encosta.

O perfil topográfico A-A' (Figura 07), apresenta uma visualização das encostas nesta unidade. Caracteriza-se por conter altitudes que variam de $380 \mathrm{~m}$ (A) na porção sudoeste e nordeste, à 340m próximo ao canal fluvial. O relevo ondulado, caracteriza o canal de drenagem encaixado, estando estes próximos a cabeceiras de drenagem, levando à um fluxo de água rápido.

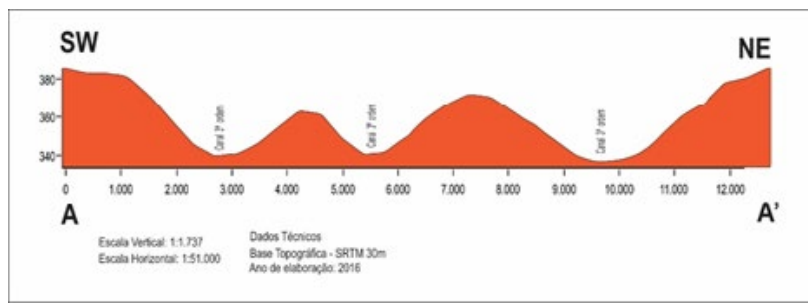

Figura 07- Perfil topográfico A-A’ na BHRJ.

Org: Os autores, 2016.

\subsubsection{Unidade Associação de Morros e Morrotes}

A unidade Associação de Morros e Morrotes apresentam-se como a segunda maior unidade de relevo na bacia hidrográfica. Com uma área de $1.482,63 \mathrm{~km}^{2}$, a unidade representa $28,79 \%$ da área total. A unidade está associada ao rebordo do planalto, com altitudes que variam de $160 \mathrm{~m}$ à superiores de $400 \mathrm{~m}$, com declives maiores que $15 \%$, sendo uma região de transição entre o Planalto Meridional e a Depressão Periférica.

As formas de vertentes Côncavo - Divergente e Convexo - Divergente apresentam-se predominante nesta unidade, caracterizando a região de transição geomorfológica do relevo, e o aumento da velocidade do fluxo de água nos canais de drenagem.

O perfil topográfico B-B' (Figura 08), caracteriza a transição geomorfológica entre o Planalto Meridional e a Depressão Periférica. Os canais de drenagem apresentam 
elevadas variações altimétrica, que acarreta na intensidade do escoamento da água, influenciando nos processos erosivos.

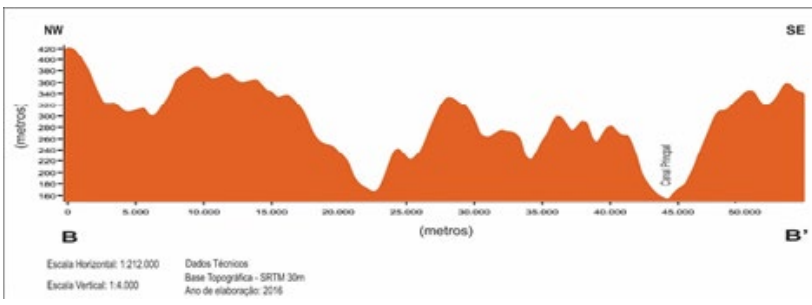

Figura 08- Perfil topográfico B-B' na BHRJ.

Org: Os autores, 2016.

\subsubsection{Unidade Colinas Suavemente Onduladas}

A unidade Colinas Suavemente Onduladas, apresenta-se com uma área de $944,44 \mathrm{~km}^{2}$, representando $18,33 \%$ da área total. A unidade está associada à declives entre $2-5 \%$, próxima a foz do Rio Jaguari, estando situado na transição entre o rebordo do planalto e áreas planas, com altitudes que variam de $100 \mathrm{~m}$ à superiores de $140 \mathrm{~m}$.

Esta unidade caracteriza-se por amplitudes altimétricas menores que $100 \mathrm{~m}$, que marcam no relevo porções onduladas, próximas à região do Rebordo e ao canal principal. As formas das encostas Côncavo - Divergente e Convexo - Divergente distribuem-se pela unidade, caracterizando o relevo às porções planas, mas com a presença de Morros e Morrotes Isolados.

O perfil D-D' topográfico (Figura 09), apresenta uma visão das características da variação altimétrica e da amplitude de $40 \mathrm{~m}$ desta unidade. Nessas condições, devido à pouca declividade, os sedimentos trazidos do Planalto Meridional e do Rebordo do Planalto, depositam-se próximo as margens aos canais de drenagem, influenciando na formação de bancos de areia isolados e consequentemente diminuindo a velocidade de escoamento da água.

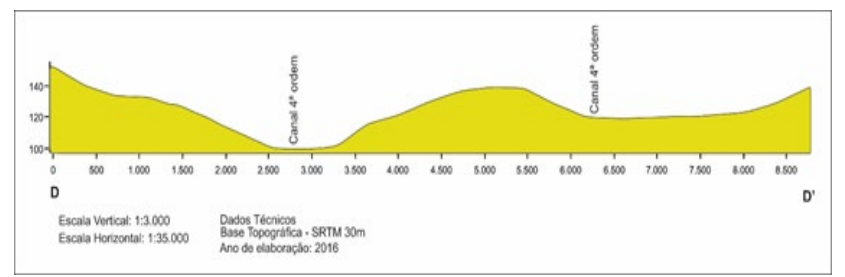

Figura 09- Perfil topográfico D-D’ na BHRJ. Org: Os autores, 2016.

\subsubsection{Unidade Áreas Planas}

A unidade Áreas Planas apresenta-se com uma área de 253,69 $\mathrm{km}^{2}$, representando 4,92\% da área total. A unidade está associada à altitude baixas e declives menores que $2 \%$, situada na região sul da bacia hidrográfica. Em regiões com essas características, propicia a deposição de sedimentos ao longo do canal fluvial e na redução da velocidade do fluxo da água. As formas de vertentes Convexa - Convergente, influencia no comportamento da drenagem, resultando em um escoamento lento. Esta unidade, caracteriza-se com baixa variação altimétrica, ocorrendo deposição no canal principal, e inundações na várzea, com altitudes que variam de $90 \mathrm{~m}$ à $100 \mathrm{~m}$.

\subsubsection{Unidade Morros e Morrotes Isolados}

A unidade de Morros e Morrotes Isolados apresenta uma área de $44,77 \mathrm{~km}^{2}$, representando cerca de $0,89 \%$ dá área total da bacia hidrográfica. A unidade representa Morros e Morrotes, com declives maiores que $15 \%$ e com cotas altimétricas maiores que 120 metros. As formas das vertentes Côncavo - Convergente, nessa unidade, caracteriza pela concentração do fluxo de água, sendo mais propenso ao carregamento de sedimentos no decorrer do canal principal. O perfil topográfico C-C' (Figura 10), caracteriza um Morro próximo ao canal principal à margem direita, com amplitude aproximada de 80 metros. O Morro em análise, situa-se em região plana e próxima às Colinas Suavemente Onduladas, o que influencia no carregamento de matérias para o rio, e caracteriza o tipo de vegetação existente na área da BHRJ.

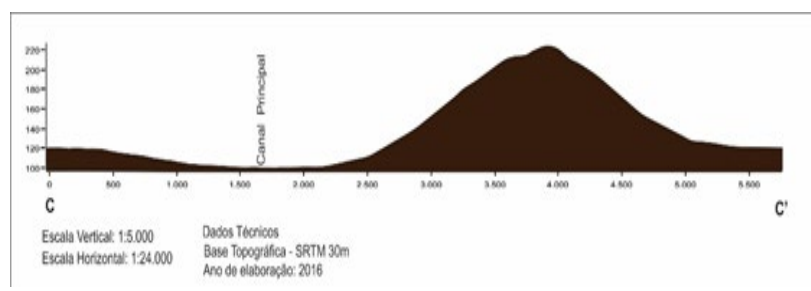

Figura 10- Perfis topográfico C-C’ na BHRJ. Org: Os autores, 2016.

\section{CONSIDERAÇÕES FINAIS}

A análise e mapeamento das Unidades de Relevo na BHRJ, permite ao pesquisador entender a intensidade em que os fenômenos naturais ocorrem no espaço geográfico.

A BHRJ distribui-se por vários municípios da região oeste, apresentando em diversas áreas, diferentes formas do relevo, que acabam influenciando no modo de uso e ocupação do solo.

Entender os processos de transformação da paisagem, correlacionando as formas de relevo com um levantamento cartográfico, contribui para o planejamento e ordenamento do espaço natural, de modo equilibrado. 


\section{REFERÊNCIAS}

BOTELHO, R. G. M. Planejamento Ambiental em Microbacia Hidrográfica. In: GUERRA, A.J.T; SILVA, A.S.; BOTELHO, R.G.M. (Orgs.) Erosão e conservação dos solos: conceitos, temas e aplicações. Rio de Janeiro: Bertrand Brasil, 1999.

CHRISTOFOLETTI, A. Geomorfologia. $2^{a}$ ed. São Paulo: Edgard Blücher, 1980.

DE NARDIN, D; ROBAINA, L.E.S. Mapeamento de Unidades de Relevo no Oeste do RS: O caso da Bacia Hidrográfica do Arroio Miracatú. Anais do XI Simpósio Brasileiro de Geografia Física Aplicada - USP, 2005. p3576- 3588 .

DIAS. D.F. Proposta de Atlas Geoambiental para o município de Mata -RS. Trabalho de Graduação. Universidade Federal de Santa Maria, 2014. 131p.

HUGGETT, R.J. Soil landscape systems: A model of soil genesis. Geoderma, Amsterdan, v. 13, p. 1-22, 1975.

MACMILLAN, R. A.; SHARY, P. A., Landforms and landform elements in geomorphometry. In: HENGL, T. e REUTER, H. I. (eds), Geomorphometry-Concepts, Software, Applications. Developments in Soil Science, vol. 33, Elsevier, Amsterdam, 2009. Pag. 227-254.

MUÑOZ, V. A. Análise geomorfométrica de dados SRTM aplicada ao estudo das relações solo-relevo. Instituto Nacional de Pesquisas Espaciais, São José dos Campos, 2009. 112p. (INPE-15796-TDI/1531). Dissertação (Mestrado em Sensoriamento Remoto). - Instituto Nacional de Pesquisas Espaciais.

ROSS, J.L.S. O registro cartográfico dos fatos geomórficos e a questão da taxonomia do relevo. Revista do Departamento de Geografia, São Paulo, n ${ }^{\circ}$ 6, 1992. p. 17-29.

SCCOTI, A.A.V; ROBAINA, L.E.S; TRENTIN, R. Compartimentação do relevo no município de Manoel Viana RS. Ciência e Natura, Santa Maria. ISSN: 2179-460X, v. 35 n. 1 jul. 2013, p. 064-070.

TRENTIN, R; SANTOS, L.J.C; ROBAINA, L.E.S. Compartimentação geomorfológica da bacia hidrográfica do rio Itu - Oeste do Rio Grande do Sul - Brasil. Soc. \& Nat., Uberlândia, ano 24 n. 1, 127-142, jan/abr. 2012.

TROEH, F. R. Landform equations fitted to contour maps.
American Journal Science, v. 263, p. 616-627, 1965.

\author{
;

.

